\title{
Cylindrocladium pteridis, Agente Causal de Mancha Foliar em Caryota mitis
}

\author{
Rosalee A. Coelho Netto ${ }^{1}$, Francisco A. Ferreira ${ }^{2}$ \&, Luiz A.G. Assis ${ }^{1}$ \\ Instituto Nacional de Pesquisa da Amazônia, Coordenação de Pesquisa em Ciências Agronômicas, Cx. Postal 478, \\ CEP 69011-670, Manaus, AM, e-mail: rcoelho@inpa.gov.br; ${ }^{2}$ Universidade Federal de Viçosa, Departamento de \\ Fitopatologia, CEP 36571-000, Viçosa, MG; e-mail: ffff@ mail.ufv.br
}

(Aceito para publicação em 22/05/2003)

Autor para correspondência: Rosalee A. Coelho Netto

\begin{abstract}
Cylindrocladium pteridis, the causal agent of the leaf spot of Caryota mitis

A new disease of clumping fishtail palm (Caryota mitis) was detected in Manaus, Brazil. The disease is characterized by round to

elliptical or irregular brown leaf spots with dark edges and a peripheral yellow halo. The causal agent was identified as Cylindrocladium pteridis. This is the first time that $C$. pteridis has been reported on this host.
\end{abstract}

A palmeira rabo-de-peixe ou cariota-de-touceira [Caryota mitis Loureiro (Arecaceae)] é uma espécie originária da Índia e da Malásia, bastante utilizada no Brasil com fins paisagísticos. No ano de 2002, em viveiro e em plantas adultas na cidade de Manaus, AM, foi observada a ocorrência de manchas foliares circulares a elipsoidais ou irregulares, de coloração parda, com bordas escuras, terminadas por um halo clorótico (Figura 1). Da periferia das lesões isolou-se um fungo em meio de BDA que apresentava características típicas do gênero Cylindrocladium, tais como conídios hialinos, cilíndricos, e unicelulares, haste com vesícula apical clavada e produção de microesclerócios junto ao micélio. Os seus conídios produzidos em BDA e em folhas de gerânio (Pelargonium zonale Willd) e eucalipto (Eucalyptus grandis Hill ex Maid.) inoculadas após as suas inserções em meio de BDA apresentaram variação de dimensões de 60 a $110 \mu \mathrm{m} x$ 3,6 a 6,0 $\mu \mathrm{m}$. Essas características correspondem ao fungo Cylindrocladium pteridis Wolf (Crous, P.W. Taxonomy and Pathology of Cylindrocladium (Calonectria) and Allied Genera St. Paul, APS, 2002). A sua patogenicidade foi confirmada em folhas de mudas de $C$. mitis, mantidas em casa de vegetação, inoculadas com discos de colônia em BDA, de $0,5 \mathrm{~cm}$ de diâmetro, em pontos das superfícies abaxiais com e sem leve ranhura feita com o auxílio de agulha flambada. Nas testemunhas utilizaram-se discos do mesmo meio de cultura, sem o fungo. As mudas foram cobertas com sacos plásticos transparentes, tendo as paredes internas borrifadas com água. As plantas inoculadas permaneceram em casa de vegetação, com os sacos plásticos sendo removidos $24 \mathrm{~h}$ depois. Aos quatro dias da inoculação, os primeiros sintomas surgiram nas folhas com e sem ferimento. Das lesões produzidas, $C$. pteridis foi reisolado em BDA. Assim, este é o primeiro relato da ocorrência de mancha foliar, causada por C. pteridis, em C. mitis. Entretanto, em Caryota sp., C. floridanum Sobers \& C.P. Seym. foi tido como agente causal de doença foliar, sendo a sua patogenidade demonstrada por meio de inoculação antecedida de ferimentos artificiais, (Chase \& Broschat, 1991. Disease and Disorders of Ornamental Palms).

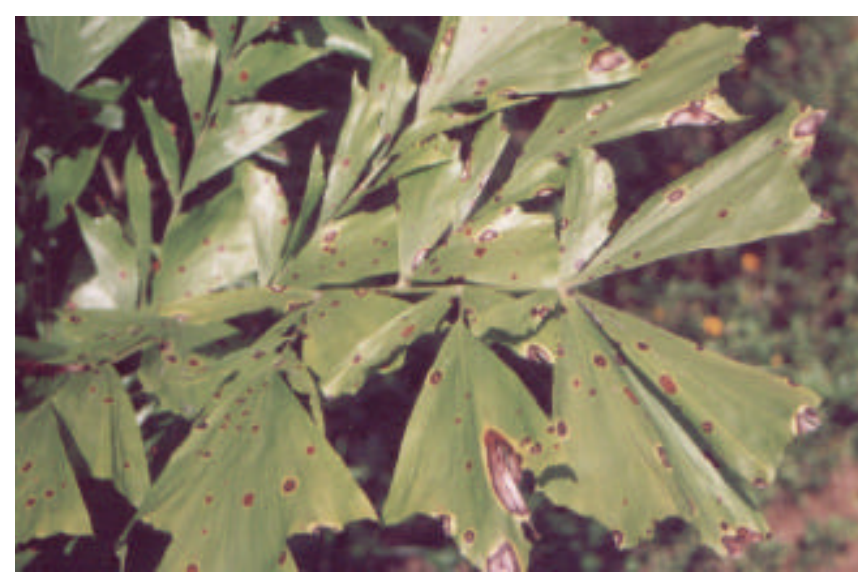

FIG. 1 - Sintomas de mancha foliar em Caryota mitis causada por Cylindrocladium pteridis. 